\section{Comparison of the results of primary and secondary implantation of flexible open-loop anterior chamber intraocular lens}

\begin{abstract}
Purpose To assess and compare the results of primary and secondary implantation of flexible open-loop anterior chamber intraocular lenses (AC-IOLs).

Methods A series of 57 eyes of 56 patients with flexible AC-IOLs were reviewed in two groups. In group I $(n=35)$ an AC-IOL was implanted primarily, because of posterior capsule problems during extracapsular cataract extraction (ECCE), and in group II $(n=22)$ secondarily after intracapsular cataract extraction (ICCE). Follow-up was from 12 to 38 months.

Results Mean post-operative best-corrected visual acuity in group I was significantly lower (20/37.38) than that of group II (20/29.20) $(p=0.044)$. Best corrected visual acuity of $20 / 40$ or better was achieved in 19 of 29 eyes $(65 \%)$ in group I, and in 16 of 21 eyes (76\%) in group II. The difference was not statistically significant $(p>0.05)$. In group II 18 eyes ( $86 \%$ ) maintained or improved visual acuity. In group I, 17 eyes (49\%) had a total of 22 complications, while 7 eyes $(32 \%)$ had 9 complications in group II $(p>0.05)$.

Conclusions Flexible open-loop AC-IOLs are suitable for both primary and secondary implantation to correct aphakia. Secondary implantation of flexible open-loop AC-IOLs
\end{abstract}

H. Bayramlar

I.F. Hepşen

O. Çekiç

A. Gündüz

Department of

Ophthalmology

Inönü University Turgut Özal

Medical Center

Malatya

Turkey

Dr Hüseyin Bayramlar Inönü Üniversitesi Turgut Özal Tıp Merkezi

Göz Hast. Anabilim Dalı

Malatya

Turkey

Tel: +90422 3255857

Fax: +904223410610
HÜ SEYIN BAYRAMLAR,

IBRAHIM F. HEPSEN, OSMAN ÇEKIC, ABUZER GÜNDÜZ

loop AC-IOLs is between $0.25 \%$ and $0.70 \%$, it is about 5 times lower with flexible open-loop ACIOLs (between $0.06 \%$ and $0.16 \%)^{1}$

Some surgeons prefer to implant flexible open-loop AC-IOLs in the absence of posterior capsular support, ${ }^{5,6}$ while others advise sutured posterior chamber (PC) IOLs. ${ }^{7,8}$ Despite some advantages of scleral fixation of PC-IOLs - such as safety in the long term because it preserves the corneal endothelium, minimising aniseikonia in contralateral eyes that are phakic or pseudophakic with a PC-IOL in place ${ }^{8-11}$ they also have some disadvantages. For example, suturing technique is more difficult than with AC-IOL implantation and the surgery takes longer. Intraocular manipulation is often excessive, even with newer, improved techniques.

We use flexible open-loop one-piece AC-IOLs when the posterior capsule or its remnants cannot support the lens. In this study we assessed and compared the outcomes of primary and secondary implantation of these lenses.

\section{Material and methods}

This retrospective study, spanning December 1993 to January 1997, evaluated the results of AC-IOL implantation in two groups. In group I ( $n=35$ eyes of 34 patients), an AC-IOL was implanted primarily in cataract surgery because of posterior capsule complications encountered during ECCE. Capsule complications in this group included $32(91 \%)$ posterior capsule ruptures and vitreous loss and $3(9 \%)$ zonular dialyses. In all cases with vitreous loss, vitrectomy was performed by a Kaufmann vitrector or sponge-and-scissors. The eyes that received a PC-IOL after vitreous loss are not included. Thirty-four Ophtec AC260T AC-IOLs (Ophtec, Groningen, Holland) and one Hanita OPAB16 AC-IOL (Kibbutz, Hanita, Israel), which all are one-piece PMMA lenses, were implanted in this group. All eyes were followed for at least 12 months (range 12-38 months).

In group II there were 22 aphakic eyes of 22 patients that had all had previous ICCE surgery 
elsewhere. All eyes received an Ophtec AC260T IOL. The size of the AC-IOL to be implanted was determined by adding $1 \mathrm{~mm}$ to the horizontal white-to-white iris diameter. A lens guide was used to prevent iris tuck and uveal chafing in all cases. Time between cataract extraction and secondary IOL implantation ranged from 11 months to 6 years (mean 2.8 years). An anterior vitrectomy was performed in 10 cases of this group to remove all formed vitreous from the anterior chamber. All eyes were followed for at least 12 months (range 12-31 months).

Patient age at surgery ranged from 18 to 85 years (average 63.3 years) in group I and from 18 to 79 years (average 61.3 years) in group II.

\section{Results}

Six patients in group I and one in group II had significantly decreased vision for reasons unconnected with the surgery: retinitis pigmentosa ( 2 cases), agerelated macular degeneration (1 case in each group), diabetic maculopathy (1 case), glaucomatous optic atrophy (1 case) and post-traumatic vitreoretinopathy (1 case). In analysing visual outcomes these cases were excluded.

Mean best corrected visual acuity (VA) in group I was $20 / 37.38 \pm 20 / 80.97$, and in group II was $20 / 29.20 \pm 20 / 78.74$. The difference was statistically significant (unpaired Student's $t$-test, $p=0.044$ ). Of 29 cases in group I, 19 eyes (65\%) had $20 / 40$ or better corrected VA, 9 eyes (31\%) had 20/50 to 20/200 VA, and 1 eye (3\%) had 20/400 VA. Of 21 cases in group II, 16 eyes $(76 \%)$ had $20 / 40$ or better VA, and 5 eyes $(24 \%)$ had $20 / 50$ to $20 / 200 \mathrm{VA}$. The difference in the number of eyes with VA of $20 / 40$ or better between the groups was not statistically significant (chi-squared test, $p>0.05$ ). In group II 6 eyes gained 2 or more Snellen lines, 12 gained or lost 1 line or less, and 3 lost 2 or more lines. Overall, 18 eyes $(86 \%)$ maintained or improved visual acuity.

Table 1 shows the complications encountered. In group I, 17 eyes (49\%) had a total of 22 complications, while 7 eyes (32\%) had 9 complications in group II. Although group II had a markedly lower complication rate, the difference between the groups was not statistically significant (chi-squared test, $p>0.05$ ). No cases of explantation, loop malplacement, retinal detachment, vitreous haemorrhage, iridodialysis or uveitis were encountered in this study.

\section{Discussion}

There are a number of favourable reports on flexible open-loop AC-IOLs in the literature, ${ }^{5-7,12}$ but few have compared primary and secondary implantations. ${ }^{5,13}$ In this study we tried to compare primary and secondary AC-IOL implantations.

Nineteen of 29 eyes $(65 \%)$ in our primary implantation group (group I) achieved a best corrected VA of $20 / 40$ or better. This result is comparable with previous studies. In the literature this good VA level has been reported in from $35 \%$ to $82 \%$ of primary implantations. ${ }^{5,6,13-15}$

In terms of VA results, the cases that had secondary IOL insertion following uncomplicated ICCE had more favourable outcomes than the cases with primary IOL implantation that underwent complicated ECCE. These results are consistent with those of David et al. ${ }^{13}$ They reported that $56 \%$ of eyes with secondary implantation following uncomplicated ICCE achieved a good VA (20/40 or better), compared with $35 \%$ of cases that underwent complicated ECCE. In our study, this lower rate of good VA in primary cases was associated with the complicated surgery, and it may be due to prolonged surgical time and increased inflammation.

The percentage of eyes achieving a final VA equal to or better than their best corrected pre-operative VA was $86 \%$ in group II. This is consistent with those previous studies that reported a high rate of good vision. ${ }^{5-7,16-19}$ The reduction in best corrected VA may be due to cystoid macular oedema, although that was not clearly diagnosed in this group.

In this study there were no serious per-operative problems in either group. Sight-threatening complications consisted of cystoid macular oedema ( 2 in group I and 1 in group II), 1 secondary glaucoma in group I, and 1 pseudophakic bullous keratopathy in group I. Both the severe and total complication rates were higher in group I, and this was associated with a higher vitreous loss rate that necessitated vitrectomy and prolonged the surgery time. Eyes undergoing primary AC-IOL implantation are already at a significantly greater risk of cystoid macular oedema, retinal detachment and post-operative inflammatory glaucoma. Patients undergoing secondary AC-IOL implantation are

Table 1. Complications

\begin{tabular}{lcc}
\hline & $\begin{array}{c}\text { Primary AC-IOL implantation } \\
(n=35)\end{array}$ & $\begin{array}{c}\text { Secondary AC-IOL implantation } \\
(n=22)\end{array}$ \\
\hline Intraoperative haemorrhage into anterior chamber & $5(14)$ & $3(14)$ \\
Pupil deformation & $11(31)$ & $5(23)$ \\
Cystoid macular oedema & $2(6)$ & $14)$ \\
Vitreous prolapse into anterior chamber & $5(14)$ & - \\
Glaucoma & $1(3)$ & - \\
Pseudophakic bullous keratopathy & $1(3)$ & - \\
Total complications & $22(63)$ & $9(41)$ \\
Total eyes with complications & $17(49)$ & $7(32)$ \\
\hline
\end{tabular}

Values are the number (\%). 
presumably a healthier group of eyes that have been preselected on the basis of their visual potential, and absence of inflammation, glaucoma or anterior chamber abnormalities including peripheral anterior synechiae. In their study, David et al. ${ }^{13}$ found lower rates of cystoid macular oedema and pseudophakic bullous keratopathy in the secondary implantation group. Weene ${ }^{5}$ also reported no retinal complications in secondary implantation cases. He proposed that this might be due to the vitreous liquefaction and posterior detachment that occurs in most cases of aphakia, especially after 1 year. ${ }^{5,20}$ This may explain why the results of secondary implantation are better when 1 or more years have elapsed after cataract surgery, as was the case in the current series. ${ }^{21}$ The complications in the secondary implantation group, such as intraoperative haemorrhage, pupil deformation and cystoid macular oedema, may be related to sizing and placement of the lens implant rather than the presence of the lens itself.

Because of the high complication rate and explantation rate of first-generation closed-loop AC-IOLs, ${ }^{22}$ some surgeons advocate implanting scleralfixated PC-IOLs and not using AC-IOLs in the absence of a posterior capsular support., ${ }^{3,-25}$ In their prospective comparative study, however, Bellucci et al. ${ }^{7}$ found a higher complication rate in scleral-fixated lenses than in open-loop AC-IOLs. The surgical technique of scleralfixated lenses requires elaborate skills and aggressive intraocular manipulations, not always mastered by the average cataract surgeon. However, flexible open-loop AC-IOLs are easier and faster to implant in the anterior chamber, and vitreous manipulation is usually not necessary. ${ }^{26}$ Eleven eyes (50\%) in our study required vitrectomy for vitreous loss during secondary lens implantation. When vitreous is lost during cataract surgery, sufficient and painstaking vitreous cleaning is necessary to obtain more favourable results in secondary and especially primary AC-IOL implantation.

In conclusion, using an open-loop, flexible AC-IOL for both primary and secondary implantation is a suitable way to treat aphakia. On the basis of this study, secondary implantation of flexible open-loop AC-IOLs after ICCE seems to have more favourable visual outcomes and lower complication rates overall than primary implantation. Further studies including larger series and longer follow-up may help us to draw this conclusion more clearly.

\section{References}

1. Lim ES, Apple DJ, Tsai JC, et al. An analysis of flexible openloop anterior chamber lenses with special reference to the normalised rate of lens explantation. Ophthalmology 1991;98:243-6.

2. Apple DJ, Price FW, Gwin T, et al. Sutured retropupillary posterior chamber intraocular lenses for exchange or secondary implantation. The 12th annual Binkhorst Lecture, 1988. Ophthalmology 1989;96:1241-7.

3. Hu BV, Shin DH, Gibbs KA, Hong YJ. Implantation of posterior chamber lens in the absence of capsular and zonular support. Arch Ophthalmol 1988;106:416-20.
4. Solomon K, Gussler JR, Gussler C, Van Meter WS. Incidence and management of complications of transsclerally sutured posterior chamber lenses. J Cataract Refract Surg 1993;19:488-93.

5. Weene LE. Flexible open-loop anterior chamber intraocular lens implants. Ophthalmology 1993;100:1636-9.

6. Rattigan SM, Ellerton CR, Chitkara DK, Smerdon DL. Flexible open-loop anterior chamber intraocular lens implantation after posterior capsule complications in extracapsular cataract extraction. J Cataract Refract Surg 1996;22:243-6.

7. Bellucci R, Pucci V, Morselli S, Bonomi L. Secondary implantation of angle-supported anterior chamber and scleral-fixated posterior chamber intraocular lenses. J Cataract Refract Surg 1996;22:247-52.

8. Miyake K, Asakura M, Kobayashi H. Effect of intraocular lens fixation on the blood-aqueous barrier. Am J Ophthalmol 1984;98:451-5.

9. Apple DJ, Mamalis N, Loftfield K, et al. Complications of intraocular lenses: a historical and histopathological review. Surv Ophthalmol 1984;29:1-54.

10. Stark WJ, Gottsch JD, Goodman DF, et al. Posterior chamber intraocular lens implantation in the absence of capsular support. Arch Ophthalmol 1989;107:1078-83.

11. Holladay JT. Evaluating the intraocular lens optic. Surv Ophthalmol 1986;30:385-90.

12. Anmarkrud N, Bergaust B, Bulie T, Sand AB. Evaluation of a flexible one-piece open-loop anterior chamber lens Symflex 350B' 3-4 years after implantation. Acta Ophthalmol (Copenh) 1993;71:796-800.

13. David R, Yagev R, Schneck M, Briscoe D, Gilad E, Yassur Y The fate of eyes with anterior chamber intra-ocular lenses. Eur J Ophthalmol 1993;3:42-6.

14. Pearson PA, Owen DG, Maliszewski M, Smith TJ. Anterior chamber lens implantation after vitreous loss. Br J Ophthalmol 1989;73:596-9.

15. Ersöz TR, Özgan Y, Özdemir N, Yagmur M, Sen N. Ön kamara lensi implante edilen gözlerde prognoz. Med Network Ophthalmol (Turkey) 1997;4:300-3.

16. Hayward JM, Noble BA, George N. Secondary intraocular lens implantation: eight year experience. Eye 1990;4:548-56.

17. Nielsen IS, Johansen J. Secondary lens implantation. Acta Ophthalmol (Copenh) 1988;66:552-5.

18. Wong SK, Koch DD, Emery JM. Secondary intraocular lens implantation. J Cataract Refract Surg 1987;13:17-20.

19. Ellerton CR, Rattigan SM, Chapman FM, Chitkara DK, Smerdon DL. Secondary implantation of open-loop, flexible, anterior chamber intraocular lenses. J Cataract Refract Surg 1996;22:951-4.

20. Heller MD, Straatsma BR, Foos RY. Detachment of the posterior vitreous in phakic and aphakic eyes. Mod Probl Ophthalmol 1972;10:23-26.

21. Shammas HJF, Milkie CF. Cystoid macular edema following secondary lens implantation. J Am Intraocul Implant Soc 1981;7:40-2.

22. Auffarth GU, Wesendahl TA, Brown SJ, Apple DJ. Are there acceptable anterior chamber intraocular lenses for clinical use in the 1990s? Ophthalmology 1994;101:1913-22.

23. Malbran E, Malbran E Jr, Negri I. Lens guide suture for transport and fixation in secondary IOL implantation after intracapsular cataract extraction. Int Ophthalmol 1986;9:151-60.

24. Grehn F, Sundmacher R. Fixation of posterior chamber lenses by transscleral sutures: technique and preliminary results. Arch Ophthalmol 1989;107:954-5.

25. Sen HA, Smith PW. Current trends in suture fixation of posterior chamber intraocular lenses. Ophthalmic Surg 1990;21:689-95.

26. Koenig SB, Apple DJ, Hyndiuk RA. Penetrating keratoplasty and intraocular lens exchange: open-loop anterior chamber lenses vs sutured posterior chamber lenses. Cornea 1994;13:418-21. 